\title{
Escravidão, reprodução endógena e crioulização: o caso do Espírito Santo no Oitocentos
}

\author{
Adriana Pereira Campos
}

\section{RESUMO}

O presente artigo avalia a importância da família escrava na sociedade brasileira do Oitocentos, especialmente da reproduçáo endógena propiciada por tal tipo de enlace, tomando como referência a Província do Espírito Santo no período. Consideraram-se dois recortes temporais, 1790-1821 e 18501872, para a análise das fontes e comparação dos dados relativos às famílias escravas. Buscou-se realizar a identificação da composição sexual e etária das escravarias capixabas, enfocando a regiáo abrangida pela Comarca de Victoria no primeiro quartel do século e incluindo, no segundo quartel, a Comarca de Itapemirim, devido à importância adquirida pela cafeicultura na regiấo sul da Província à época. Como base nesses levantamentos, discutiu-se a crioulizaçáo dos cativos em terras capixabas e o crescimento vegetativo como elemento de sobrevivência demográfica da escravidão no Espírito Santo.

Palavras-chave: escravidão; família escrava; demografia, Brazil, século XIX.

\section{ABSTRACT}

This paper evaluates the importance of the slave family in the Brazilian society of the Nineteenth century, especially the endogenous reproduction provided by this kind of arrangement, with regard to the Espirito Santo Province (located in Brazil's east coast) during the period. Two time sections, 1790-1821 and 18501872, were considered in evaluating the sources and in comparing the slave families' data. Besides that, both the gender and the age composition of the slave population were identified, focusing, initially, in the region covered by the Province's capital, Victoria, during the first quarter of the century. In the second quarter, the analysis includes the southern Itapemirim county due to the importance attained by its coffee growing activity in the Province's overall economy. From the database collected, the paper discusses the so-called crioulização of captives, as well as their demographic growth, as elements of survival of the slavery system in Espirito Santo at that time.

Keywords: slavery, slave family, demography, Brazil, Nineteenth century. 


\section{Introdução}

O presente artigo avalia a importância da família escrava na sociedade brasileira do Oitocentos, especialmente a reprodução endógena propiciada por tal tipo de enlace, tomando como referência a Província do Espírito Santo no período. Para tanto, consideraram-se dois recortes temporais, 17901821 e 1850-1872, para a análise das fontes e a comparação dos dados relativos às famílias escravas. Decidiu-se ainda adotar a década de 1790 como o marco inicial do primeiro recorte, em vista do renovado interesse sobre o Espírito Santo por parte da Coroa Lusitana à época. Verifica-se, nas recomendaçôes do Secretário de Estado da Marinha e Ultramar, D. Rodrigo de Sousa Coutinho (o futuro Conde de Linhares), ênfase na exploração de novos territórios e na implantação de culturas para a geração de prosperidade e riqueza, destacando-se aí os rios mais importantes da colônia, dentre os quais o Rio Doce em terras capixabas ${ }^{1}$.

O Oitocentos viria se caracterizar pela superação do quadro de isolamento e pobreza que marcou profundamente a Capitania no século anterior. A década de 1790, desse modo, afina-se mais com os anos do século vindouro, dada a retomada da dinâmica econômica que então se inicia no território. Por outro lado, optou-se pelo encerramento do primeiro recorte no ano de $1821 \mathrm{com}$ a finalidade de manter a amostragem dentro do período colonial e, assim, evitar qualquer heterogeneidade que a nova situaçáo do país tenha proporcionado à dinâmica econômica local. Já o segundo recorte se deveu à importância da lei de supressão do tráfico (1850) e da Lei do Ventre Livre (1872), responsáveis por alteraçôes demográficas inegáveis sobre a população cativa.

\section{A população escrava na Província do Espírito Santo no século XIX}

A Província do Espírito Santo, ao longo do Oitocentos, apresentava população reduzida, atingindo pouco menos de um por cento dos habitantes do Brasil. Em 1790, contava apenas 22.493 indivíduos, atingindo, porém, 82.137 almas em 1872. A população escrava, nesses totais, variou, conforme pode ser constatado na Tabela 1 .

O Gráfico 1 a seguir revela a curva ascendente da população escrava da Província do Espírito Santo, com dois momentos de elevação. O primeiro se dá em 1824 e o segundo entre 1856 e 1872.

Tabela 1. População da Província do Espírito Santo, 1790-1872

\begin{tabular}{|c|c|c|c|}
\hline Anos & Livres & Escravos & Total \\
\hline 1790 & $10749^{*}$ & $6834^{*}$ & 22493 \\
\hline 1824 & 22165 & 13188 & 35353 \\
\hline 1856 & 36793 & 12100 & 48893 \\
\hline 1872 & 59478 & 22659 & 82137 \\
\hline
\end{tabular}

Fontes: Capitão-Mor Ignacio João Mongiardino (apud OLIVEIRA, José T. de. História do Estado do Espírito Santo. Vitória: Arquivo Público do Estado do Espírito Santo. Nota IV, p. 239); VASCONCELLOS, Ignacio Accioli de. Memoria statistica da Provincia do Espirito Santo escrita no anno de 1828. Vitória: Arquivo Público Estadual, 1978; RELATÓRIO do Presidente de Província - Barão de Itapemirim de 25 de maio de 1857; IBGE. Censo de 1872.

* A informação fornecida pelo Capitão-Mor Mongiardino não soma a população total da Província, mas apenas das vilas da Victoria, do Espírito Santo, Nova Almeida, Benevente e Guarapari. 
Gráfico 1. População da Província do Espírito Santo, 1790-1872

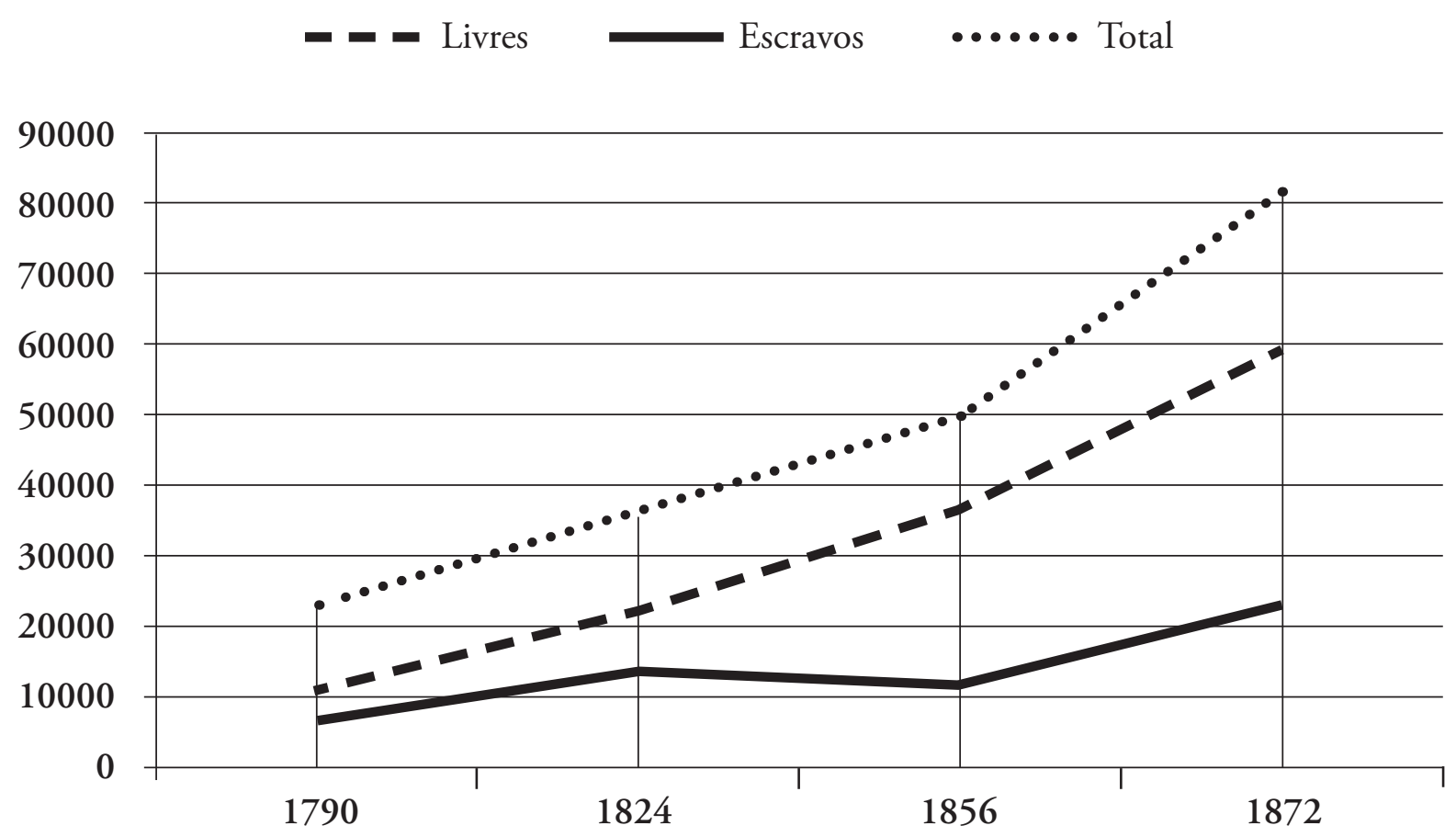

A explicação mais provável para o pico populacional das primeiras décadas do século relaciona-se à explosiva demanda por escravos contatada na América nos anos de 1820 do século XIX. Segundo Ada Ferrer², a revolução escrava do Haiti, ocorrida em 1791, e a crescente pressão britânica pelo fim do tráfico sustentaram a expansão da escravidão no início do Oitocentos. Cuba emergiu, nesse contexto, como colônia escravista e agroexportadora, importando cerca de 325.000 africanos entre os anos de 1790 e 1820, e saltando sua produção de 40.000 toneladas de açúcar, em 1790, para 105.000 toneladas em 1830. Manolo Florentino observou números ainda mais expressivos para as entradas de africanos no Brasil. No Rio de Janeiro, os levantamentos do autor indicado estimam um total de 706.870 africanos desembarcados entre 1790 e 1830 .

Em escala mais modesta, a Capitania do Espírito Santo experimentou certo incremento de cativos no mesmo período, beneficiada pela crescente necessidade dos senhores de escravos em aumentar suas escravarias diante das ameaças externas de supressão do tráfico. $\mathrm{O}$ maior incremento de escravos na Província do Espírito Santo não ocorreu, porém, no primeiro quartel do século XIX. O movimento de expansão com maior destaque aconteceu após 1856. Embora a população capixaba alcançasse reduzida expressão demográfica ao longo do XIX, não ultrapassando ainda um por cento dos habitantes do país, a proporção de escravos no total de residentes da Província alcançava grande significação. Tal fato conferia à sociedade capixaba a marca distintiva da escravidão, mesmo quando comparada às economias vizinhas do que hoje se conhece como regiáo Sudeste: 


\section{Gráfico 2. População Escrava na Regiấo Sudeste do Brasil}

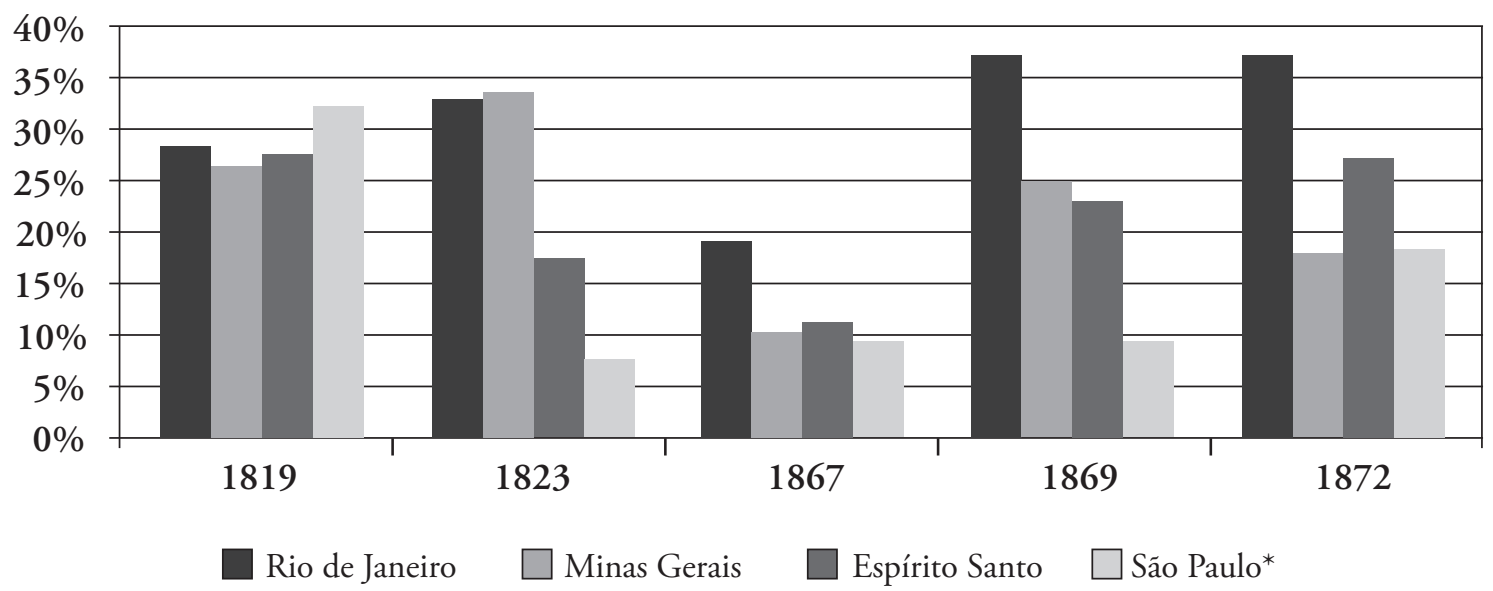

Fontes: IBGE. Estatísticas históricas do Brasil: séries econômicas, demográficas e sociais de 1550 a 1988. Rio de Janeiro: IBGE, 1990. p. 32; VASCONCELLOS, Ignacio Accioli de. Memoria statistica da Provincia do Espirito Santo escrita no anno de 1828. Op. cit.

*A população de São Paulo em 1819 foi considerada em conjunto com o Paraná. **A população do Espírito Santo, em 1823, aparece na estatística do IBGE com o total de 120 mil habitantes e 60 mil escravos, quando, em 1824, o Presidente da Província

elaborou estimativa de 13.184 escravos, essa última, a nosso ver, mais condizente com os valores apurados nos demais anos.

Assim, apreciados proporcionalmente em relação aos homens livres, a população escrava do Espírito Santo, como se viu no gráfico anterior, manteve-se significativa ao longo do século XIX. Importa salientar, porém, que a economia capixaba alterou-se e novos polos escravistas se desenvolveram no Norte e no Sul da Província. Na região Sul, a partir do segundo quartel do século, floresceu a cultura cafeeira no vale do rio Itapemirim, cuja tendência demográfica ascendente modificou a distribuição populacional da Província, em particular, dos escravos, principalmente a partir de 1872:

Tabela 2. Distribuição Populacional na Província do Espírito Santo, 1824-1872

\begin{tabular}{|l|c|c|c|c|c|c|}
\hline \multirow{2}{*}{ Regióes } & \multicolumn{2}{|c|}{1824} & \multicolumn{2}{c|}{1856} & \multicolumn{2}{c|}{1872} \\
\cline { 2 - 7 } & Livres & Escravos & Livres & Escravos & Livres & Escravos \\
\hline Capital & 8.994 & 5.699 & 13.164 & 3.834 & 19.004 & 5.455 \\
\hline Reis Magos & 5.445 & 1.704 & 8.485 & 1.841 & 10.281 & 2.562 \\
\hline Benevente & 3.887 & 1.979 & 6.536 & 758 & 7.014 & 1.474 \\
\hline Sáo Matheus & 2.659 & 2.654 & 3.640 & 2.213 & 5.357 & 2.813 \\
\hline Itapemirim & 2.332 & 1.148 & 4.968 & 3.454 & 17.822 & 10.355 \\
\hline Total ES & 23.317 & 13.184 & 36.793 & 12.100 & 59.478 & 22.659 \\
\hline
\end{tabular}

Fontes: (Ano de 1824) VASCONCELLOS, Ignacio Accioli de. Memoria statistica da Provincia do Espirito Santo escrita no anno de 1828. Transcrição do manuscrito original por Fernando Achiamé. Vitória: Arquivo Público Estadual, 1978; (Ano de 1856) - Censo constante do Relatório apresentado pelo José Maurício Fernandes Pereira de Barros, no dia 13 de fevereiro de 1857, p. 8; Censo de 1872.

De acordo com a Tabela 2 acima, a partir de 1856, a maior concentração de escravos na Província transferira-se da região Central, no entorno da Capital, para a regiáo Sul, particularmente na cidade de Cachoeiro do Itapemirim. Embora a populaçáo livre da Capital permanecesse em crescimento e superior ao total dos residentes de Itapemirim, o número de escravos desta última localidade ultrapassara decisivamente aquele verificado em Vitória, somando $46 \%$ do total da Província, enquanto na Capital o percentual correspondente caíra para o patamar de $24 \%$. O incremento escravista do Sul capixaba explica-se 
pela bem sucedida expansão cafeeira na região na segunda metade do século XIX. Como explicou Vilma Almada ${ }^{4}$, quando o café firmou-se como atividade mais rentável do que a cultura da cana-de-açúcar, o avanço da exploração cafeeira ligou-se diretamente ao crescimento demográfico da Província. É certo que a atividade também se espraiou para a região serrana sob o impulso da instalação de colônias de imigrantes europeus, como italianos e alemáes. Nessas áreas, porém, não ocorreu o emprego da máo-de-obra escrava, de modo que a explicação desse novo tipo de arranjo econômico escapa aos limites do presente trabalho.

\section{Escravarias e reprodução endógena}

Embora possuísse população reduzida, se considerado o número de habitantes do Brasil, a Província do Espírito Santo caracterizava-se, como se viu, pelo largo emprego de escravos. Nesse espaço de escassos recursos financeiros, encontraram-se formas de reiteração da escravidão que fugiam aos padrôes tradicionais do tráfico. Desde o início do século, as escravarias, de modo geral, tinham número equivalente de homens e mulheres, enquanto no Rio de Janeiro "os homens representavam 55\% a dois terços de toda a escravaria"', entre 1790 a 1830. A razáo de masculinidade, no Rio de Janeiro desse período, variou entre 141 a $228^{6}$. Nessa mesma época, o indicador para a Capitania do Espírito Santo oscilou entre 74 e 1387, de modo que o seu máximo sequer atingiu o valor mínimo observado no principal centro escravista do Brasil.

O primeiro indício da singularidade do escravismo em terras capixabas é fornecido pela estimativa populacional produzida no ano de 1824, na qual se registrou a existência de $7.016(53,2 \%)$ cativos e 6.175 (46,8\%) cativas. De um estoque de 13.188 escravos em 1824, a Província saltou para 22.659 cativos em 1872, não obstante a composição sexual desse novo contingente permanecesse equilibrada. Os homens somavam, na época, 11.859 (52,3\%) indivíduos e as mulheres, 10.800 (47,7\%). Cachoeiro do Itapemirim, município da região sul da Província, também apresentava população com notável equilíbrio de sexos, apesar de se afigurar fronteira agrícola e sediar unidades produtoras do tipo plantation $^{8}$. Lá existiam $4.222(56,4 \%)$ escravos e 3.260 (43,6\%) cativas, enquanto a razão de masculinidade mantinha-se no patamar de 129, de acordo com o censo de 1872.

Tabela 3. Origem dos Escravos no Espírito Santo

\begin{tabular}{|l|c|c|c|c|}
\hline \multirow{2}{*}{ Origem } & \multicolumn{2}{|c|}{$\mathbf{1 7 9 0 - 1 8 1 9}^{9}$} & \multicolumn{2}{c|}{$\mathbf{1 8 5 0 - 1 8 7 1}$} \\
\cline { 2 - 5 } & número & $\%$ & número & $\%$ \\
\hline Crioulo & 1.266 & 77,8 & 880 & 60,3 \\
\hline Naçáo & 0 & 0 & 81 & 5,6 \\
\hline Angola & 331 & 20,3 & 32 & 2,2 \\
\hline Benguella & 6 & 0,4 & 3 & 0,2 \\
\hline Congo & 5 & 0,3 & 8 & 0,5 \\
\hline Mina & 18 & 1,1 & 5 & 0,3 \\
\hline Moçambique & 0 & 0 & 6 & 0,4 \\
\hline Cariboca & 0 & 0 & 2 & 0,1 \\
\hline Cabinda & 0 & 0 & 1 & 0,1 \\
\hline Canange & 0 & 0 & 1 & 0,1 \\
\hline Ceuláo & 1 & 0,1 & 1 & 0,1 \\
\hline Total Parcial & 1.627 & 86,6 & 1.020 & 69,9 \\
\hline Sem identificaçáa & 252 & 13,4 & 439 & 30,1 \\
\hline Total Geral & 1.879 & 100 & 1.459 & 100 \\
\hline
\end{tabular}

Fonte: Inventários post-mortem do Cartório de $1^{\circ}$ Ofício de Vitória. 
A explicação para tal balanceamento entre os sexos nas escravarias pode se relacionar diretamente à origem dos escravos existentes na Província do Espírito Santo. Sem estimativas da população africana em solo capixaba para o início do século, recorreu-se, primeiramente, a inventários post-mortem para se qualificar a origem dos cativos, como descrito na Tabela 3 acima.

Observa-se grande contingente de crioulos nos dois períodos analisados, enquanto os africanos caíram de $22,2 \%$, no primeiro intervalo, para 9,6\% dos escravos no segundo. Em termos comparativos, a Bahia ${ }^{10}$ vivenciava situação oposta à do Espírito Santo à época. No período de 1790 a 1821, verificou-se grande importação de africanos na Bahia, acarretando forte aumento na razão de masculinidade naquela Província, tendo o indicador chegado a 226. Por outro lado, a Capitania de Sergipe de El-Rey ${ }^{11}$, na fronteira norte da Bahia e que, afastada do eixo principal do tráfico atlântico de escravos, possuía razão de masculinidade em torno de 120. Explica o estudioso que essa cifra "mais baixa deveu-se à alta proporção de cativos nascidos no Brasil na população". No contingente sergipano de escravos, os africanos perfaziam um terço do contingente das escravarias.

A região central da Província que se desenvolveu a partir do núcleo urbano e rural de Victória, embora dispusesse de diversos cais marítimos e fluviais, mantinha-se ligada aos grandes portos do país, sobretudo, Rio de Janeiro e Salvador por meio da navegaçáo de cabotagem. A exportaçáo do ano de 1826 e 1827 configura o quadro geral mercantil da Província por meio da comercialização, principalmente, de alimentos. A renda obtida pela venda da farinha de mandioca (119:700\$000) correspondia a quatro vezes o valor alcançado com o açúcar $(31: 554 \$ 000)$ e a oito vezes com fio de algodáo $(14: 336 \$ 000)^{12}$. Para o Espírito Santo, o Rio de Janeiro remetia carne, farinha de mandioca, trigo, roscas, sal, queijo, louça, mobília etc. ${ }^{13}$. Para o interesse deste artigo, dentre esses produtos, no ano de 1827 , importaram-se 100 escravos, ao preço médio de $250 \$ 000$, o elemento de maior valor de despesa dos capixabas e responsável pelo segundo maior gasto de conjunto. Os 25 contos despendidos com cativos só perdiam para os 88 contos com fazendas secas. A importação trazia novos contingentes de africanos, mas, de acordo com os inventários post-mortem, menos de um quarto dos cativos possuía tal procedência como se depreende da Tabela 4, mais abaixo. Buscava-se, certamente, introduzir mais cativos masculinos que, entre os africanos, alcançava a razáo de masculinidade de 176 . O contingente reduzido de africanos, porém, pouco modificava a realidade local que permanecia com taxa de 118 .

O equilíbrio sexual das escravarias na Capitania do Espírito Santo, entre 1790 e 1819, relaciona-se, portanto, à baixa importação de africanos ${ }^{14}$. Enaile Carvalho ${ }^{15}$ evidenciou que a Capitania, no início do século XIX, desenvolvera economia vinculada à produção de alimentos e de algodão, voltada aos mercados consumidores do Brasil, além de atender às necessidades de subsistência local. Os protagonistas dessas atividades eram lavradores com plantaçôes próprias, roceiros ou sitiantes que lograram amealhar modestas fortunas. Alguns poucos fazendeiros e negociantes destacavam-se dentre esses agricultores, sem alcançar, contudo, riquezas vultosas, se comparadas com o patrimônio dos homens de "grossa aventura" que descreve, por exemplo, João Luiz Ribeiro Fragoso para o Rio de Janeiro $^{16}$. Na Capitania do Espírito Santo, no alvorecer do Oitocentos, a escravidão disseminava-se nesse cenário de senhores de modesta fortuna. Quase metade dos escravos (43,3\%) era empregada na pequena lavoura de alimentos.

Tabela 4. Escravos no Espírito Santo por Sexo e Origem, 1790-1819

\begin{tabular}{|l|c|c|c|}
\hline Origem & Mulheres & Homens & Total \\
\hline Crioulo & 619 & 647 & 1266 \\
\hline \multirow{2}{*}{ Africanos } & 140 & 247 & 387 \\
\cline { 2 - 4 } & 759 & 894 & 1653 \\
\hline
\end{tabular}

Fonte: Inventários post-mortem do Cartório de $1^{\circ}$ Ofício de Vitória. 
Na segunda metade do século XIX, a taxa de africanidade dos escravos da Província do Espírito Santo, segundo o censo de 1872, apresentava-se na casa dos 10\%, perfazendo 2.262 africanos. Essa cifra, naquele período, colocava-se entre as mais elevadas do país. Dos inventários post-mortem analisados entre os anos de 1850 a 1871, encontrou-se a taxa de 9,6\% de africanos entre os escravos da regiáo central da Província, cujo polo mais importante era a capital, Victoria ${ }^{17}$. A taxa de masculinidade de 300 entre os africanos das escravarias examinadas era muito alta para o período posterior ao fim do tráfico, o que reforça a hipótese de comércio ilegal na regiáo. $\mathrm{O}$ expediente resultou em certo aumento da taxa geral de masculinidade para 130 na região central da Província, mas não chegou a interferir na razoável paridade dos sexos nas escravarias. A tabela a seguir colabora para a elucidação da questão:

\section{Tabela 5. Escravos no Espírito Santo por Sexo e Origem, 1850-1871}

\begin{tabular}{|l|c|c|c|}
\hline Origem & Feminino & Masculino & Total \\
\hline Crioulos & 407 & 471 & 878 \\
\hline \multirow{2}{*}{ Africanos } & 35 & 105 & 140 \\
\cline { 2 - 4 } & 442 & 576 & 1018 \\
\hline
\end{tabular}

Fonte: Inventários post-mortem do Cartório de $1^{\circ}$ Ofício de Vitória.

Apenas o Rio de Janeiro superava a marca de africanidade nas escravarias capixabas, que invertera assim a sua situaçáo, se comparada com o início do século quando se afigurava como terra de poucos africanos. Cachoeiro de Itapemirim, nessa época, possuía 1.255 cativos africanos, mais da metade do contingente da Província. Estima-se que parte desses homens tenha acompanhado seus senhores quando chegaram às terras do sul do Espírito Santo. Nara Saletto ${ }^{18}$ explica que tais senhores de escravos mecanizaram apenas parcialmente as tarefas relacionadas ao café, de sorte que o aumento da produção dependia, portanto, da intensificaçáo da exploração do trabalho escravo. A ampliação do número de cativos correspondia diretamente ao ímpeto de crescimento dos cafezais, principalmente, na região Sul da Província.

Embora a taxa de africanidade fosse alta no segundo quartel do Oitocentos, quando, em tese, o tráfico cessara, a reiteraçáo da escravaria não podia se sustentar somente por essa via. Assim, ao lado da paridade sexual nas escravarias e do predomínio dos crioulos sobre os africanos, chama atenção a reprodução endógena na Província do Espírito Santo. No início do século XIX, o censo de 1827 já indicava o fato. Nasceram, naquela data, 474 escravos e morreram 300. Os inventários dos anos 1790 a 1819 e 1850 a 1871 ilustram de forma cabal o crescimento vegetativo indicado, como pode se deduzir dos Gráficos 3 e 4, abaixo.

\section{Gráfico 3. Distribuição etária e sexual dos escravos, Espírito Santo, 1790-1819.}

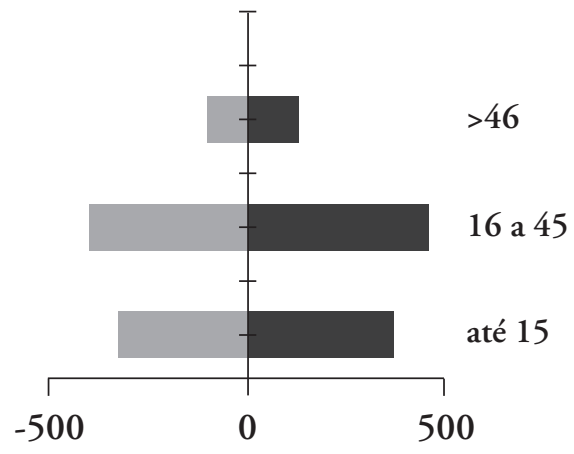

Mulheres
Homens
Gráfico 4. Distribuição etária e sexual dos escravos, Espírito Santo, 1850-1872.

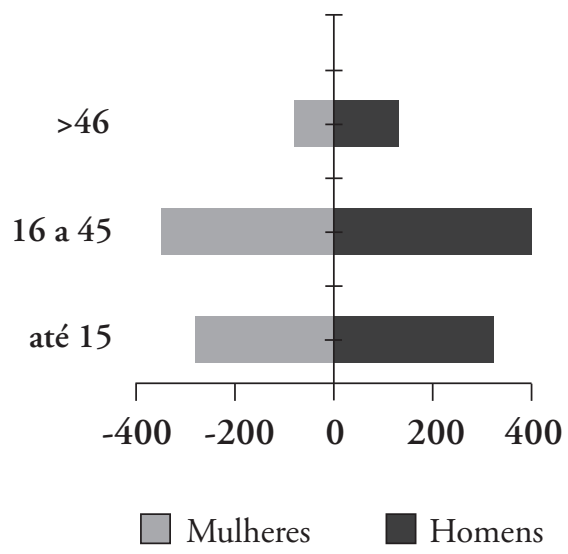


No ano de 1872, na regiáo de Vitória, o censo apontou 43,6\% de crianças de 1 a 15 anos e 52,6\% de adultos de 16 a 40 anos $^{19}$. Nos inventários levantados para o período de 1850 a 1872, encontrou-se distribuição etária, na qual 38,7\% dos escravos tinham de 1 a 15 anos e 47,6\%, de 16 a 45 anos. Em Cachoeiro do Itapemirim, o censo de 1872, apresentava população jovem mais reduzida, contando apenas com 22,4\% dos escravos de 1 a 15 anos, enquanto os adultos de 16 a 50 anos somavam 62,6\%, tal como se representa no Gráfico 5 abaixo:

Gráfico 5. Distribuição etária e sexual dos escravos, Cachoeiro do Itapemirim, 1872

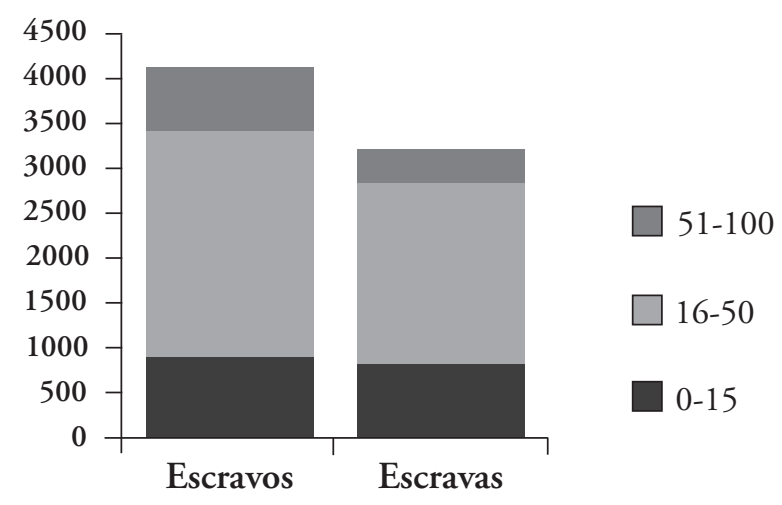

A região Sul, conclui-se, dispunha de uma população com relevante cota de adultos, como resultado do acelerado processo de expansão da fronteira do café do Vale do Paraíba em direção à Província do Espírito Santo. Os cativos chegavam acompanhados de seus senhores, ou por meio do tráfico interprovincial para reforçar as propriedades recém instaladas ${ }^{20}$. A presença de escravos adultos e africanos explica-se pela afluência de senhores do Norte Fluminense, regiáo que se abastecera crescentemente do tráfico antes da supressão do mesmo. O padrão das escravarias cachoeirenses, no entanto, mantinha a baixa razão de masculinidade de 120 .

Indaga-se, contudo, se a presença de crianças com idade até 15 anos, que já constituíam quase um quarto do plantel, não significaria a reprodução endógena desses cativos? Na Paróquia de S. Pedro do Cachoeiro, de acordo com o censo de 1872, existiam 378 escravos casados ou viúvos, dentre 1.947 indivíduos. O percentual de escravos casados nessa paróquia alcançava 17,9\%, enquanto na Província, no mesmo período, registrava 14,3\%. Já na Paróquia de N. S. da Victoria observou-se situação distinta, pois apenas $8,9 \%$ dos escravos constavam como casados. Vilma Almada verificou que dentre os nubentes inscritos nos arquivos da Paróquia de S. P. de Cachoeiro, apenas 12,3\% eram de escravos e metade deles pertencia a uma única fazenda, a Monte Líbano ${ }^{21}$. A explicação, portanto, para a disparidade entre as duas paróquias reside no fato de que quase todos os escravos daquela fazenda encontrarem-se casados. Tal constatação denota certo desestímulo, por parte dos outros senhores, ao casamento oficial.

Os números referentes às uniōes entre escravos e à constituição de famílias, porém, podem ser inferidos por meio dos inventários. Dessas fontes, apurou-se a média de 6,7\% de escravos arrolados como casados, perfazendo um conjunto de cerca de 120 casais. Em detalhes, pode-se afirmar que, entre os anos de 1790 a 1819, 24,5\% dos 1.879 escravos arrolados estavam aparentados. Desses 460 indivíduos, havia 286 filhos e filhas, 139 mães, 31 pais e 4 avós. Das 868 escravas, localizou-se $16 \%$ de mulheres na qualidade de mães de algum cativo. Para os anos de 1850 a 1871, 22,6\% dos 1.456 escravos possuíam algum laço consanguíneo. Havia 236 filhos e filhas, 75 mães, 17 pais e 2 avós arroladas nos inventários. De 658 mulheres cativas, 11,4\% tinha seu nome vinculado a filhos. É interessante notar que elas majoritariamente localizavam-se na faixa etária de 15 a 40 anos, o que aumenta o índice dessas mulheres envolvidas com a maternidade. Levando-se em conta que, entre 
1790 a 1819, 130 mães tinham de 16 a 40 anos e 385 mulheres situavam-se na faixa etária de 15 a 46 anos, isso significa um envolvimento com a maternidade da ordem de 33,8\%. No outro período pesquisado, 1850-1871, a taxa caiu para 20,6\%.

Os dados apresentados tornam evidente a capacidade reprodutora das escravarias capixabas ao longo do Oitocentos. Majoritariamente, tais unidades eram compostas por escravos crioulos, com estável equilíbrio dos sexos e com elevado índices de crianças. Com essas características, observa-se que, ao longo do século, cada 100 escravos aptos a trabalhar alimentavam cerca de 70 cativos com até 14 anos ou com mais de 64 anos de idade. Sabe-se que o modelo produtivo dos grandes plantadores no século XIX dispunha de um grau de dependência muito menor, da ordem de 100 escravos para 30 cativos fora da idade produtiva ${ }^{22}$.

No inventário de Joana Pereira das Neves, por exemplo, datado de 1856, encontra-se escravaria de 37 cativos, dentre os quais 20 indivíduos com idade de poucos meses até 15 anos. Algumas famílias escravas possuíam até cinco filhos declarados em inventários, como a de Feliciana, crioula de 30 anos cuja prole figurava no rol sob sua filiação. Outro cativo, o crioulo Francisco, de 58 anos, segundo informaçáo do mesmo inventário, tinha três filhos e era casado com Anna, de 50 anos, cuja origem náo consta do documento. A idade dos filhos desse casal distava sensivelmente. Davi tinha 16 anos, Benefácia, 10, e Jesuína apenas 2. Já as idades dos filhos de Feliciana eram muito próximas. Eduvirges tinha 19 anos; Rita, 18; Justino, 13; Maximiliano, 10; e Nazário, 8. A família de Feliciana se estendia a duas netas, Lucrécia, 3 anos e Ludesnina, 1 ano, filhas de Eduvirges. A particularidade de ambos os casos afigura-se na antiguidade das famílias, cujas mães contavam com mais de 40 anos e podiam desfrutar da companhia dos netos.

O inventário de D. Joana Pereira das Neves notabiliza-se pela juventude de sua escravaria, em que se arrola a filiação de dezoito infantes. Outras doze crianças, todavia, não receberam indicação de paternidade. Pode-se imaginar que o fato resultasse apenas da omissão dos nomes dos pais por parte do testamenteiro. Deve-se, porém, discutir a hipótese de aquisição desses meninos e meninas por meio do comércio, cuja elucidação implica a busca de informaçóes em documentos relativos à compra de escravos $^{23}$. Nos livros de Notas de Compra e Venda do Cartório de $2^{\circ}$ Ofício de Vitória, encontrou-se a distribuição dos escravos negociados na Capital, reportada no Quadro 1 abaixo.

Quadro 1. Distribuição etária e sexual dos escravos negociados em Vitória, 1861-1872

\begin{tabular}{|l|c|c|c|c|c|c|}
\hline \multirow{2}{*}{ Sexo } & \multicolumn{5}{|c|}{ Idade } & \multirow{2}{*}{ Total } \\
\cline { 2 - 6 } & $\mathbf{0 - 1 5}$ & $\mathbf{1 6 - 2 1}$ & $\mathbf{2 1 - 4 5}$ & $\mathbf{4 5 - . . .}$ & $\begin{array}{c}\text { Náo } \\
\text { declarada }\end{array}$ & \\
\hline Masculino & 31 & 23 & 44 & 11 & 5 & 114 \\
\hline Feminino & 26 & 19 & 39 & 9 & 13 & 106 \\
\hline Total & 57 & 42 & 83 & 20 & 18 & 220 \\
\hline
\end{tabular}

Inspecionando-se os números mais detalhadamente, nota-se que, dos 220 escravos negociados, os homens respondiam por $51,2 \%$ da preferência, enquanto as mulheres somavam 48,8\%. Mantinha-se, assim, a distribuição sexual tradicional do lugar. As crianças correspondiam a 25,9\% dos escravos negociados com idade declarada, pouco mais de uma quarta parte do contingente. Poder-se-ia justificar pelo baixo preço a procura por escravos de pouca idade, contudo, os dados mostram que o valor das crianças nem sempre era barato, bastando observar o Quadro 2 a seguir: 
Quadro 2. Distribuição etária dos escravos negociados em Vitória, 1861-1872

\begin{tabular}{|c|c|c|c|c|c|c|c|}
\hline \multicolumn{2}{|c|}{} & \multicolumn{5}{c|}{ Idade } & \multirow{2}{*}{ Total } \\
\cline { 3 - 8 } \multicolumn{2}{|c|}{} & $0-15$ & $16-21$ & $21-45$ & $45-\ldots$ & $\begin{array}{c}\text { Náo } \\
\text { declarada }\end{array}$ & \\
\hline \multirow{4}{*}{$\begin{array}{c}\text { Valor } \\
\text { mil-réis }\end{array}$} & $0-500$ & 17 & 1 & 9 & 16 & 1 & 44 \\
\cline { 2 - 8 } & $501-1000$ & 19 & 18 & 39 & 3 & 8 & 87 \\
\cline { 2 - 8 } & $1001-1500$ & 14 & 19 & 23 & 1 & 5 & 62 \\
\cline { 2 - 8 } & $1501 \ldots$ & 7 & 4 & 12 & 0 & 4 & 27 \\
\hline \multicolumn{2}{|c|}{ Total } & 57 & 42 & 83 & 20 & 18 & 220 \\
\hline
\end{tabular}

É possível afirmar, entâo, que a reprodução endógena avançava além da reiteração da escravaria, convertendo-se em expediente de alto valor no mercado de almas. No quadro acima, verifica-se que $39,5 \%$ dos cativos eram negociados na faixa de um conto a um conto e meio de réis, dentre os quais quase $1 / 4$ se constituía de crianças. Poder-se-ia imaginar que, de cada quatro escravos negociados na praça de Victoria, um era criança de até 15 anos.

Os inventários apontam quase todas as mulheres escravas envolvidas com a gestação ou a criação de filhos. No inventário de Raphael Maxado Fraga, por exemplo, datado de 1801, há uma escravaria de 44 cativos, dentre os quais 19 têm até 15 anos. Algumas famílias escravas possuíam até cinco filhos declarados em inventários, como a de Vicente, crioulo de 30 anos, cujos cinco filhos se apresentavam arrolados sob sua filiação e não da mãe, sequer mencionada. Outro cativo, o crioulo André, segundo informação do mesmo inventário, possuía três filhos e esposa, nomeada Benedita, cuja origem e idade não constam do documento. A particularidade de ambos os casos se afigura no rol dos filhos de cativos, caracterizando a paternidade das crianças. Todavia, sete cativas aparecem com seus respectivos filhos sem indicação dos pais. Havia, entretanto, outros oito cativos desprovidos de vínculo familiar. De qualquer modo, reconhece-se, em geral, que os avaliadores costumavam vincular as crianças às mães. Assim, os casos de Vicente e André constituiriam exceçôes à dita regra. Importa aqui, de fato, ressaltar o grande contingente de crianças nessa escravaria.

Em inventário de 1804 são arrolados o genro e a filha de Raphael Maxado Fraga. Neste documento pode-se observar a evoluçáo do plantel de escravos da família, assim como a partilha dos bens entre os herdeiros de Maxado. Em primeiro lugar, verifica-se que nem o crioulo Vicente e nem tampouco seus filhos constavam da escravaria de Francisco Pereyra Pinto, genro de Maxado, indicando que essa família escrava não fora dividida durante a repartição do patrimônio. Já o casal de crioulos, André e Benedita, foram arrolados como escravos do casal inventariado, assim como duas de suas filhas. Em relação à crioula Caetana, não só permaneceu ela com suas crianças mais novas, José e Marcelino, como também aumentou sua prole com o nascimento dos gêmeos Adáo e Eva e uma criança de colo. Outras escravas herdadas pelo genro de Maxado continuaram com seus filhos, sugerindo que o ato de partilha dos bens de um senhor morto náo resultava necessariamente no fracionamento das famílias escravas, fossem elas matrilineares, como visto em outras partes do Brasil, fossem elas patrilineares, como no exemplo de Vicente e André.

Já em 1815, no inventário do Capitão-Mor Ignacio Pereira Barcellos, criador de rebanhos equinos, bovinos e ovinos, consta a maior escravaria arrolada nos inventários levantados no Cartório de $1^{\text {a }}$. Vara de Órfãos de Vitória. Dentre seus 119 escravos, chama atenção a família formada pelo angola Antonio, declarado com 52 anos, e pela crioula Anastacia, 50 anos. Esse casal tinha quatro filhas, a saber: Maria, de 11 anos; Teodora, de 7 anos; Vitória, de 3 anos e Ana, de 25 anos. Essa última, por sua vez, dera à luz quatro netos de Antonio e Anastacia ou, mais precisamente: Angélica, com 14 anos; Serafim, com 
5 anos; Adam, com 3 anos e Antônia, com 4 anos. Embora Anastacia e sua filha, Ana, tivessem sua primeira paridela muito distante dos demais partos, cujas razóes não se explicam nas fontes estudadas, constata-se a estabilidade dessa família escrava pelo período de pelo menos vinte e cinco anos. Apesar da morte de Ignacio, o destino dessa família permaneceu quase inalterado, pois apenas a filha mais velha de Ana converteu-se em herança de um dos filhos do Capitão-Mor. Os demais integrantes continuaram na companhia da viúva, talvez pelos poucos anos de vida que ainda restavam a Antonio, já doente na época, e a Anastácia, ambos com idade avançada, não só para os padrões daquele tempo como também para os dos próprios escravos em geral.

A estabilidade das famílias nas escravarias garantia aos senhores fator reprodutivo da força-de-trabalho. Num lugar de negócios mais acanhados, como Victoria, ou em fronteiras agrícolas, como Cachoeiro, percebe-se certo padrão da posse cativa com alguma proporção entre homens e mulheres em cada propriedade. Nota-se também importante contingente de crianças nas escravarias. Os senhores beneficiavam-se da reprodução endógena para obter parte desses infantes. O comércio, como se viu, contribuía no mesmo sentido. Não foi ainda possível determinar a origem das crianças, mas se pode levantar a hipótese de se tratar de distribuição local para o equilíbrio das demandas de cada propriedade. O jornal da Victoria registrou, em 27 de outubro de 1867, às 13h30, os gritos e o tropel que se seguiram ao pregão de venda e arremate de escravos próximos à redação do periódico. Da porta, os jornalistas observaram tratar-se de duas crianças que corriam para fugir do senhor que as comprara. Pela descrição oferecida pelos jornalistas, a aquisição de infantes no pelourinho constituía-se em cena comum na cidade.

\section{Consideraçóes finais}

Neste artigo objetivou-se apresentar a dinâmica demográfica da populaçáo escrava na Província do Espírito Santo durante o período de recrudescimento da escravidão nas Américas, ao longo do século XIX. Demonstrou-se que, à época, a sociedade capixaba apresentava elevado percentual de escravos, mantendo-se, entre as províncias brasileiras, como aquela com maior contingente de cativos, mesmo após o fim do tráfico em 1850. O desenvolvimento da agricultura de alimentos para consumo local ou nacional, assim como de produtos de exportação, a exemplo do café, realizou-se com base na mão-deobra escrava, excetuando-se apenas a regiáo de montanhas, para onde se encaminharam os primeiros imigrantes italianos e alemáes chegados à Província no segundo quartel do Oitocentos.

Observou-se igualmente que o desenvolvimento da agricultura capixaba na primeira metade do século XIX não dispunha de capital suficiente para adquirir com regularidade os africanos desembarcados nos portos brasileiros. Predominavam nas escravarias da Província os crioulos. Quando o café impulsionou a economia da regiáo, o tráfico já havia cessado e o ingresso de africanos trazidos de outros pontos do país não foi capaz de modificar a paisagem humana anterior, sobressaindo-se ainda os crioulos entre os escravos.

O desafio no presente artigo consistiu em discutir a sobrevivência da escravidão em terras capixabas, mesmo desprovida do abastecimento proporcionado pelo tráfico transatlântico de africanos. As fontes coligidas, entre inventários e notas cartoriais, contribuem para verificar a constituição de laços familiares duradouros nas escravarias e provavelmente, até mesmo fora delas. A composição equitativa entre os sexos dos escravos no Espírito Santo ao longo do XIX, inclusive na fronteira sul da cultura cafeeira, facilitava a formação de vínculos consanguíneos entre os escravos. Desses enlaces advinha o segundo traço distintivo da escravidão em terras capixabas - o crescimento vegetativo. As cativas crioulas ocupavam boa parte de suas vidas com a maternidade e a criação de filhos. De fato, as fontes mostram que a natalidade chegava a movimentar cerca de uma quarta parte do comércio escravista praticado na praça de Victoria. Pode ser que parcela dessas crianças nem fosse nascida exatamente na província, mas 
elas eram crioulas, não africanas, o que reforça a hipótese de a escravidão ter se reproduzido em certos lugares do Brasil principalmente por meio do crescimento endógeno dos cativos, figurando o tráfico apenas como elemento suplementar dessa dinâmica. Novo lugar deve ser dado à família escrava na reflexão acerca da reprodução da escravidão no Brasil, cujos aspectos demográficos encontram-se ainda subestimados nos estudos sobre o tema.

\section{Notas}

${ }^{1}$ ALMEIDA, Eduardo de Castro (Org.). Inventário dos documentos relativos ao Brasil existentes no Arquivo dos documentos relativos ao Brasil existentes no Arquivo de Marinha e Ultramar de Lisboa (8 vol). Rio de Janeiro, 1913-36. [Inventário IV, 46 da BN].

${ }^{2}$ FERRER, Ada. Cuban Slavery. Atlantic Antislavery Review, Volume XXXI, Nº 3, 2008, p. 267-296.

${ }^{3}$ FLORENTINO, Manolo. Em costas negras: uma história do tráfico atlântico de escravos entre a África e o Rio de Janeiro (Séculos XVIII e XIX). Rio de Janeiro: Arquivo Nacional, 1995. p. 58.

${ }^{4}$ ALMADA, Vilma Paraíso Ferreira de. Escravismo e transição: o Espírito Santo, 1850-1888. Rio de Janeiro: Ediçōes Graal, 1984.

${ }^{5}$ FLORENTINO, Manolo Garcia; GOÉS, José Roberto. A paz nas senzalas: famílias escravas e tráfico atlântico. Rio de Janeiro: c. 1790-1850. Rio de Janeiro: Civilização Brasileira, 1997, p. 61.

${ }^{6}$ Informaçáo obtida em inventários post-mortem constantes em FLORENTINO, Manolo Garcia. Em costas negras: uma história do tráfico atlântico de escravos entre a África e o Rio de Janeiro (Séculos XVIII e XIX). Rio de Janeiro: Arquivo Nacional, 1995. Apêndice 33, p. 295.

${ }^{7}$ Informação obtida em inventários post-mortem guardados no Cartório de $1^{\circ}$ Ofício de Vitória.

${ }^{8}$ ALMADA, Vilma Paraíso Ferreira de. Op. cit.

${ }^{9}$ Pretendia-se realizar levantamento até o ano de 1821 , mas dificuldades de acesso ao arquivo do Cartório de $1^{\circ}$ Ofício de Vitória impediram o cumprimento do objetivo inicial da pesquisa.

${ }^{10}$ SCHWARTZ, Stuart B. Segredos internos: engenhos e escravos na sociedade colonial, 1550-1835. Sáo Paulo: Companhia das Letras, 1988. p. 290.

${ }^{11}$ SCHWARTZ, Stuart B. Op. cit.

${ }^{12}$ VASCONCELLOS, Ignacio Accioli de. Memoria statistica da Provincia do Espirito Santo escrita no anno de 1828. Transcrição do manuscrito original por Fernando Achiamé. Vitória: Arquivo Público Estadual, 1978.

${ }^{13}$ LOBO, Eulalia Maria Lameyer. História do Rio de Janeiro: do capital comercial ao capital industrial e financeiro. Rio de Janeiro: IBMEC, 1978. p. 88.

${ }^{14}$ Discuti a composição das escravarias capixabas em CAMPOS, Adriana Pereira. Escravidão e crioulização: a Capitania do Espírito Santo. In: FRAGOSO, João Luis Ribeiro; FLORENTINO, Manolo Garcia; SAMPAIO, Antonio Carlos Jucá de; CAMPOS, Adriana Pereira (Orgs.). Nas rotas do Império: eixos mercantis, tráfico e relaçôes sociais no mundo português. Vitória: EDUFES; Lisboa: IICT, 2006. p. 571-608.

${ }^{15}$ CARVALHO, Enaile Flauzina. Política e economia mercantil nas terras do Espirito Santo (1790 a 1821). Dissertação de Mestrado apresentada no Programa de Pós-graduação Stricto Sensu em História da Universidade Federal do Espírito Santo. Vitória, Espírito Santo, 2008. p. 121.

${ }^{16}$ FRAGOSO, João Luís Ribeiro. Homens de grossa aventura: acumulação e hierarquia na praça mercantil do Rio de Janeiro (1790-1830). Rio de Janeiro: Arquivo Nacional, 1992.

${ }^{17}$ A região compunha-se das seguintes paróquias: N. S. da Victoria, São José do Queimado, São João de Cariacica, São João de Carapina, Santa Leopoldina, N. S. da Conceição de Vianna, Santa Izabel, N. S. do Rosário do Espírito Santo, N. S. de Conceição da Serra.

${ }^{18}$ SALETTO, Nara. Transição para o trabalho livre e pequena propriedade no Espirito Santo: 1888-1930. Vitória: Edufes, 1996. p. 64.

${ }^{19}$ Por meio de inventários post-mortem depositados no Arquivo do Tribunal de Justiça do Espírito Santo, Patrícia Merlo encontrou dados percentuais semelhantes, confirmando a veracidade da amostragem analisada. Ver MERLO, Patricia Maria da Silva. O nó e o ninho: estudo sobre a família escrava no Espírito Santo, 1800-1871. Tese de Doutorado apresentada no Programa de Pós-graduação Stricto Sensu em História Social da Universidade Federal do Rio de Janeiro. Rio de Janeiro, 2008.

${ }^{20}$ ALMADA, Vilma Paraíso Ferreira de. Op. cit., p.118. 
${ }^{21}$ Idem, ibidem, p. 141.

${ }^{22}$ MACHADO, Cacilda; ENGEMANN, Carlos; FLORENTINO, Manolo Garcia. Entre o geral e o singular: histórias de fazendas escravistas da América do Sul - séculos XVIII e XIX. In: FLORENTINO, Manolo Garcia e MACHADO, Cacilda. Ensaios sobre a escravidão. Belo Horizonte: Editora da UFMG, 2003. p. 167.

${ }^{23}$ Ver SALETTO, Nara. Op. cit., p. 75.

\section{Referências Bibliográficas}

ALMADA, Vilma Paraíso Ferreira de. Escravismo e transição: o Espírito Santo, 1850-1888. Rio de Janeiro: Ediçóes Graal, 1984. p.118.

CARVALHO, Enaile Flauzina. Politica e economia mercantil nas terras do Espírito Santo (1790 a 1821). Dissertação de Mestrado apresentado no Programa de Pós-graduação Stricto Sensu em História da Universidade Federal do Espírito Santo. Vitória, Espírito Santo, 2008.

FERRER, Ada. Cuban Slavery. Atlantic Antislavery Review, Volume XXXI, n. 3, 2008, p. 267-296.

FLORENTINO, Manolo Garcia. Em costas negras: uma história do tráfico atlântico de escravos entre a África e o Rio de Janeiro (Séculos XVIII e XIX). Rio de Janeiro: Arquivo Nacional, 1995.

FLORENTINO, Manolo Garcia; GOÉS, José Roberto. A paz nas senzalas: famílias escravas e tráfico atlântico. Rio de Janeiro: c. 1790-1850. Rio de Janeiro: Civilização Brasileira, 1997.

FRAGOSO, João Luís Ribeiro. Homens de grossa aventura: acumulação e hierarquia na praça mercantil do Rio de Janeiro (1790-1830). Rio de Janeiro: Arquivo Nacional, 1992.

FRAGOSO, João Luís Ribeiro; FLORENTINO, Manolo Garcia; SAMPAIO, Antonio Carlos Jucá de; CAMPOS, Adriana Pereira (Orgs.). Nas rotas do Império: eixos mercantis, tráfico e relaçóes sociais no mundo português. Vitória: EDUFES; Lisboa: IICT, 2006.

FLORENTINO, Manolo Garcia e MACHADO, Cacilda. Ensaios sobre a escravidão. Belo Horizonte: Editora da UFMG, 2003.

LOBO, Eulalia Maria Lameyer. História do Rio de Janeiro: do capital comercial ao capital industrial e financeiro. Rio de Janeiro: IBMEC, 1978.

MERLO, Patricia Maria da Silva. O nó e o ninho: estudo sobre a família escrava no Espírito Santo, 1800-1871. Tese de Doutorado apresentada no Programa de Pós-graduaçáo Stricto Sensu em História Social da Universidade Federal do Rio de Janeiro. Rio de Janeiro, 2008.

SALETTO, Nara. Transição para o trabalho livre e pequena propriedade no Espirito Santo: 1888-1930. Vitória: Edufes, 1996.

SHWARTZ, Stuart B. Segredos internos: engenhos e escravos na sociedade colonial, 1550-1835. São Paulo: Companhia das Letras, 1988.

VASCONCELLOS, Ignacio Accioli de. Memoria statistica da Provincia do Espirito Santo escrita no anno de 1828. Transcrição do manuscrito original por Fernando Achiamé. Vitória: Arquivo Público Estadual, 1978. 